\title{
NEOTERIC ADVANCES IN GRAPHENE NANOMATERIAL- BASED ELECTROCHEMICAL BIOSENSORS FOR CANCER DIAGNOSIS: A REVIEW
}

\author{
Masum Hossen, Md. Anwar Hossain and Prattay Kairy
}

\begin{abstract}
Early diagnosis of the disease can appreciably improve the survival rate or facilitate effective treatment with different modalities. In the field of disease diagnosis; nanomaterial-based biosensing and bioimaging techniques are lifting hopes for point-of-care cancer diagnosis with ultra-high selectivity and sensitivity. Graphene, including twodimensional (2D) graphene films, three-dimensional (3D) graphene architectures, Graphene dots, and graphene hybrids (GHs) nanostructures have attracted the researcher's interest in the field of biosensing and bioimaging owing to their properties. Versatile platforms of graphene nanomaterials make it as germane to detect the biomarkers at the early stage of cancer. This review selectively summarizes the recent progress in using graphene-based nanomaterials for detecting lung cancer biomarkers. Explicitly, graphene-electrochemical biosensors, which are classified according to sensing mechanisms and targets (CEA, NSE, hTERT, CYFRA21-1), are thoroughly discussed. Herewith, future scopes and challenges with other matrices, nano-scaffolds have also discoursed in the conclusion and future perspective.
\end{abstract}

Index Terms - Biosensors; Graphene; Graphene Oxide; Lung cancer; Nano-materials; Biomarkers.

This paper was received on 31 March 2019, accepted on 19 November 2019. This work was supported financially Green University of Bangladesh.

Masum Hossen is with the dept. of Electrical and Electronic Engineering, Green University of Bangladesh. E-mail: masum@eee.green.edu.bd

Anwar Hossain is with the dept. of Electrical and Electronic Engineering, Green University of Bangladesh. E-mail: anwar@eee.green.edu.bd

Prattay Kairy is working as Graduate Research Assistant in the dept. of Electrical and Computer Engineering at the University of Utah. E-mail: ab.kairy09@gmail.com

\section{INTRODUCTION}

In this going era, cancer is an eye-catching malignancy that jeopardizes human life in various ways and more than 60 human organs could be influenced by different types of cancer [1]. Cancer ranked top $2^{\text {nd }}$ (after cardiovascular diseases: CVD) cause of human deaths with the proportion of global deaths $16 \%$ estimated in 2016 [2] by World Health Organization (WHO). In 2014 about 1.7 million new cases of all cancers were diagnosed among which 6 lakh people will die of this disease in the United States [3]. However, in Europe, there were just over 3.4 million new cases of cancer in 2012 of which 1.75 million people were dead. Most cases concerned men (56\%) and 44\% were women [4]. The prevalence of this abnormality is soaring as a result of variable factors such as the modern lifestyle and the presence of carcinogens in the environment and foods. Moreover, the incidence of different types of cancers is variable in the world considering heterogeneity between gender, genetic and histological types, geographical and ethnic patterns [5]. The current diagnostic methods and long-lasting care practices do not fulfill patient requirements. On the other hand, high treatment costs are a great concern for patients [6]. Therefore, demands grow increasingly for early, precise and cost-effective detection of cancer biomarkers and subsequently prevention of malignancies. Early diagnosis of cancer is crucial for the successful treatment of the disease [52]. Highly sensitive methods are urgently needed for measuring cancer diagnosis markers present at ultra-low levels during the early stages of the disease. Such methods should facilitate early detection and an adequate selection of the treatment of diseases and should lead to increased patient survival rates. Existing diagnostic tests (e.g., ELISA) are not sensitive enough and detect proteins at levels corresponding to advanced stages of the disease. Besides, the detection of low biomarker concentrations that exist in the early stages of cancer so 
NEOTERIC ADVANCES IN GRAPHENE NANOMATERIAL BASED ELECTROCHEMICAL BIOSENSORS FOR CANCER DIAGNOSIS: A REVIEW

false negatives could be obtained [51-52]. Recently, liquid chromatography-mass spectrometry (LC-MS) based studies have been taking attention for biomarker discovery but these methods are very high-cost and technically complex for routine clinical diagnostics [7]. The biological challenges for cancer biomarker detection such as the diversity of cancer and the limited ability of a single biomarker to detect all cancers of particular organs with high specificity have encouraged researchers to spend a great deal of effort in this field. To replacing a time-consuming laboratory; smaller, faster devices are highly desired. The monitoring of cancer progress and patient therapy will be improved profoundly if the analytical results available at the patient bedside within few minutes. Biological markers (biomarkers) are interpreted as _a characteristic that is objectively measured and evaluated identically as an indicator of normal biological/pathogenic. In other words, biomarkers are quantifiable measurements of biologic homeostasis that define what is normal, thereby providing a frame of reference for predicting or detecting what is abnormal $[8,9]$. Biomarkers can be specific cells, molecules, genes and gene products, enzymes or hormones. The alterations/ abnormalities can be due to several factors, including germline or somatic mutations, transcriptional changes and posttranslational modifications [10]. They indicate the changes in the expression of a certain protein that can be measured in tissues, body fluids such as urine, sputum, and blood. Also, body temperature (a marker of fever) and blood pressure (a marker of the risk of stroke) have been used in clinical diagnostics for a long time. Table-I bellow contains common biomarkers of the different types of cancer in the human body, while Table-II summarizes the biomarker's sources, categories, sub-categories and classes [11]. In the literature, there are various cancer biomarkers, which can be categorized into the protein, hormone and cogene related cancer markers, embryonic and carbohydrate antigens and enzymatic tumor markers. Biomarkers could be used in cancer staging (grading), prognosis, risk assessment and selection of treatment. Sometimes also for the determination of an individual's risk of developing cancer such as the risk of having breast and/or ovarian cancer in women could be increased by a germline mutation (BRCA1) [51].

Lung cancer is one of the most lethal cancer forms and the second most prevalent cancer in adult men and women around the world [48]. Moreover, it is also the deadliest in both sexes, because a large part of the development of the disease may occur in an asymptomatic form, and the disease is typically manifested at advanced stages [12]. Thus, early detection is a key issue in lung cancer. Low-dose chest computed tomography (CT) scanning has been suggested as a screening tool, especially in the presence of risk factors for lung cancer [13]. This type of procedure, carried out every year, is expected to increase greatly the possibility of early-stage tumor diagnosis, contributing to the increase of the survival rate [14]. However, the technique is affected by a large rate of false positives [15]. Furthermore, the exposure to the ionizing radiation of low-dose CT might increase the risk of developing cancers. Thus, large population screening, even if limited to people considered at risk, requires an alternative solution that should be noninvasive and low cost. It is necessary to have high sensitivity along with the capability of operating in complex media. The simplicity of use should also be considered to ensure that large strata of health operators can adequately utilize the instrumentation. By the same token, materials with good attributes are also needed to be used in, to design electrodes, substrates, transducers, etc. For improved selectivity and sensitivity, bioreceptor immobilization and successful recognition of biological samples development of highly effective materials for biosensor are essential.

\section{TABLE I}

GRAPHICAL REPRESENTATION OF BIOMARKER'S SOURCES, CATEGORIES, SUB-CATEGORIES AND CLASSES.

\begin{tabular}{|l|l|l|l|}
\hline Classes & Sub_categories & Categories & Sources \\
\hline Antecedent & $\begin{array}{l}\text { Peptides, fiber } \\
\text { proteins, } \\
\text { membrane } \\
\text { proteins }\end{array}$ & protein & Blood \\
\hline $\begin{array}{l}\text { Screening } \\
\text { Biomarker }\end{array}$ & $\begin{array}{l}\text { Genes, } \\
\text { mutations, } \\
\text { DNA quality, } \\
\text { micro RNA }\end{array}$ & Genomic & Saliva \\
\hline $\begin{array}{l}\text { Diagnostic } \\
\text { Biomarker }\end{array}$ & $\begin{array}{l}\text { Glucose, } \\
\text { sucrose, glycans }\end{array}$ & $\begin{array}{l}\text { Carbo- } \\
\text { hydrate }\end{array}$ & Urine \\
\hline $\begin{array}{l}\text { Staging } \\
\text { biomarker }\end{array}$ & $\begin{array}{l}\text { Cholesterol, } \\
\text { phospholipids,A } \\
\text { cylglycerols }\end{array}$ & Lipid & $\begin{array}{l}\text { Tissue } \\
\text { cells }\end{array}$ \\
\hline $\begin{array}{l}\text { Prognostic } \\
\text { biomarker }\end{array}$ & $\begin{array}{l}\text { Relactive } \\
\text { oxygen species, } \\
\text { Dicarboxylic } \\
\text { acid }\end{array}$ & Metabolities & Faeces \\
\hline
\end{tabular}


TABLE II

COMMON BIOMARKERS OF THE DIFFERENT TYPES OF CANCER

\begin{tabular}{|c|c|}
\hline TYPE OF CANCER & BIOMARKERS \\
\hline LUNG & $\begin{array}{l}\text { NSE, CYFRA21-1, CEA, } \\
\text { SCCA, CA 125, VEGF, } \\
\text { TPA, MIR-106A-5P, MIR- } \\
\text { 141-3P, KRAS, ALK, } \\
\text { CK19, HTERT }\end{array}$ \\
\hline Prostate & $\begin{array}{l}\text { miR-103a, miR-106a, } \\
\text { miR-107, PSA, Pro2PSA, } \\
\text { GSTP1, P63, PCA3 }\end{array}$ \\
\hline LIVER & $\begin{array}{l}\text { MIR-100-5P, MIR-122, A- } \\
\text { FETOPROTEIN, HCCR-1 }\end{array}$ \\
\hline BREAST & $\begin{array}{l}\text { miR-155, miR-261, CA15- } \\
\text { 3, EGFR, VEGF165, } \\
\text { BRCA L, ERBB2, HER2, } \\
\text { MuCIN-1 }\end{array}$ \\
\hline Gastric & $\begin{array}{l}\text { miR-29c, miR-148a, } \\
\text { CA19-9, CEA }\end{array}$ \\
\hline Ovarian & $\begin{array}{l}\text { miR-92, miR-93, miR- } \\
\text { 126, HE4, Mesothelin }\end{array}$ \\
\hline Brain & $\begin{array}{l}\text { miR-10b, MGMT, COX-2, } \\
\text { p14arf }\end{array}$ \\
\hline
\end{tabular}

As a one-atom-thick planar sheet of sp2-bonded carbon atoms, graphene has received much attention in recent years in materials science due to its unusual properties, such as half-integer quantum Hall effect and ballistic and extraordinary electron transport [16,53-55]. Besides the electronic spectra, graphene also exhibits unique mechanical properties such as high mechanical strength, tunable bandgap [49]; a large surface area, high elasticity, superior in heat transfer [17] and also having the hydrophobic characteristic, chemical and mechanical stability [18]. Stoichiometric process (chemical reactions) offers a great potential to use the graphene in various applications and it enables researches to control the electronic properties as well as to enhance the electrochemical activities [19]. Oxidizing graphite can alter its chemical structure, forming functional groups at the edges and basal plane of the sheets show a better biocompatibility and transform into hydrophilic characteristics [20]. GO is defined as an oxygenated monolayer of carbon atoms (2D network of sp2 and sp3 bonded atoms), produced through the oxidation process $[21,22]$. It is really important to address and to standardize the nomenclature for graphite oxide as GTO [23] is appropriate rather than GO. This is because of the terminology usage itself indicates the graphene-based materials having completely different characteristics from its physical structure to physicochemical properties. The presence of oxygenated groups such as hydroxyl and epoxy on the basal plane and carboxyl groups at the edges have their advantages and disadvantages [24]. On one hand, the oxygencontaining groups are really useful to develop the chemical and electrochemical biosensors which promote to the attachment of biological recognition element and ease for surface functionalization. On the other hand, the oxygenated groups also limit the electrical conductivity due to its insulating nature compared to the graphene sheet [49]. Various approaches have been employed to reduce the oxygencontaining groups by chemically, thermally, hydrothermally, electrochemically to introduced to mitigate the known fact of GO that it suffers from electrical conductivity (insulating behavior) because of the high degree of oxygenated groups In general, rGO is a monolayer (2D) composed of carbon atoms where a large number of oxygenated groups in it have been removed. This article reviews recent progress in the development of electrochemical biosensors for lung cancer biomarkers based on graphene nanomaterials.

\section{Strategy OF Electrochemical Sensors:}

Amore sensitive technology platform is urgently needed to fulfill the rapid diagnosis requirements in cancer marker detection during the early stages of the disease [25]. As the classical methods (such as ELISA) for diagnosis of cancer may take several hours or even days from when tests are ordered to when results are received. These methods can be tedious, timeconsuming and often require extra care and expensive instruments [50]. This especially makes an early diagnosis of cancer more difficult for cancer patients who are admitted to an emergency department. One of the key challenges in detecting biomarkers in cancer is the lack of sensitivity. The electrochemical analysis is one of the most sensitive methods for detecting inorganic, organic and even biologic substances. It is also suitable when used in the assay of cancer biomarkers [26, 27].

An 'electrochemical biosensor' is a self-contained integrated device which is capable of providing a specific quantitative or semi-quantitative analytical information using a bio-receptor retained in direct spatial contact and it can be classified based on the transduction modes [28]. The transduction mode is a type of measurement for the electrochemical biosensor and it could be based on potentiometric, amperometric, conductometric, impedimetric or field effects transistor [29]. Each type of measurements have a specific role[49], for instance, potentiometric is based on potential difference measurement, amperometric is based on current measurement from the electrochemical redox activity, impedimetric is based on impedance measurement of analyte/target binding event, conductometric is based on based on current conduction measurement during bio-recognition event 
and the field effects transistor operates based on carrier mobility between source and drain due to electric field effect controls from the biasing gate terminal [30,31]. The application of electrochemical immunoassay is likely the most promising way to solve some of the problems concerning sensitivity, speed, selectivity and economic (one-step) measurements because an effective combination of immunochemistry coupled with electrochemistry could provide the basis of direct electrical detection for a wide range of analytes with specificity and great sensitivity [32]. In consideration its portability, low cost and high sensitivity, electrochemical sensors have become an attractive alternative to help in rapid diagnosis, providing better intervention and reducing the test-time of dissemination, which is highly beneficial in reducing patient stress [33].

\section{DIAGNOSING CANCER VIA GRAPHENE-BASED ELECTROCHEMICAL BIOSENSORS}

Due to the extremely low concentration of cancer biomarkers in tissue or blood, the sensitivity of the sensors is the key parameter for the newly developed for cancer biosensor [50]. Continuously improving the sensitivity of the sensor is the requirement of analysis testing and is currently the focus of this study. The methods for improvement of the sensitivity of immunesensors were adopted by the measurement signal amplification via enzymatic reaction, magnetic microspheres, application of nanomaterials, controlled release of electro-active regents and polymer in the film of the sensors.

Electrochemical analysis method widely used in bioassay and medical testing has high sensitivity, low detection limit, and a wide linear detection range. It is simple, rapid, convenient and utilizes minimal instrumentation [34]. Electrochemical biosensors provide the combined characterizations of the high sensitivity of the electrochemical analysis. In this genre, the integration of graphene composites with transducers have shown a remarkable improvement in physicochemical properties such as it enhances the electrical conductivity, electron transfer rate and electro-active surface area to volume ratio owing to their ultra-thin 2D characteristic, which provide an important solution for higher sensing sensitivity [35]. The high surface area of graphene $\approx 2630 \mathrm{~m} 2 \mathrm{~g}-1$ (see Table 1) extremely increases biosensor's sensing areas, analytes loading and their 2D nanostructure flat surface becomes vigorously sensitive to any changes on its surface which is important to capture a biological event at nano-scale environments [36]. The technology to integrate 2D nanomaterials with transducers have brought a great opportunity in medical fields for disease detection because of their end-product exhibits high selectivity and sensitivity to detect a variety of biological analytes [37]. The analytical summary of graphene-based materials that bridges transducers for heart disease, lung cancer, asthma, and diabetes detection in term of the target molecule, immobilization matrixes, deposition technique, the electrochemical principle as well as their performances [49]. Further elucidation of each disease and the development of transducers using graphene-based materials as well as their performance can be found below sub-sections.

\section{LUNG CANCER DETECTION}

According to the world cancer report by WHO, in 2012 , the estimated numbers of new cases for all types of cancer reached more than 14 million and 8 million alone for cancer-related deaths including males and females around the globe. Among all types of new cases, lung cancer is the top rank holder with $13 \%$ where breast cancer takes second place with $11.9 \%$ of the total new cases [38]. Lung cancer is defined as an uncontrollable growth of abnormal cells in one or both lungs. The dysfunction cells in the lung will lead to the formation of a lump like tissue/mass that generally known as tumor and it is called metastasis when the cancer cells spread to other parts of the body. The highly related lung cancer biomarkers are shown in Figure 1. SCLC (small cell lung cancer) and NSCLC (non-small cell lung cancer) are the two most common types of lung cancer that appear in the human body according to the American Cancer Society. In comparison with, NSCLC is more malignant accounts for approximately $80 \%$ - $85 \%$ meanwhile SCLC represents about $10 \%$ to $15 \%$ malignancies $[39,40]$. The carcinoembryonic antigen (CEA) is widely accepted as a tumor biomarker and the marker is highly associated with diseases such as lung cancer, ovarian cancer, colon cancer, breast cancer, and pancreatic cancer. Where CEA is a glycoprotein with a molecular mass of $\sim 200 \mathrm{kDa}$ and categorized as SCLC [41-43].

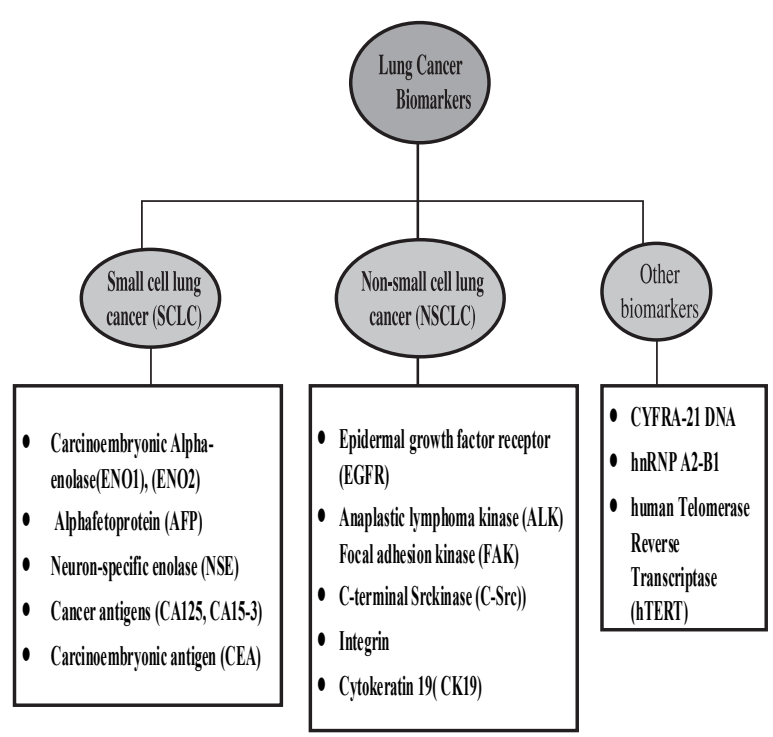

Figure 01: Highly related biomarkers for lung cancer detection. 
In this section, we rundown the recent developments of electrochemical sensors based on graphene-based transducers for carcinoembryonic antigen (CEA) detection associated with lung cancer. A flexible electrochemical paper-based biosensor was developed by using poly (4 ethylene dioxythiophene): poly (styrene sulfonate) (PEDOT: PSS) and reduced graphene oxide (rGO) composite for CEA detection [41]. They prepared (PEDOT: PSS + ethylene glycol + rGO) aqueous suspension and dipped the Whatman paper into the solution for $1 \mathrm{~h}$ and then dried at $100{ }^{\circ} \mathrm{C}$ in a hot air oven followed by the treatment with ethylene glycol for 20 minutes and drying the paper at $100{ }^{\circ} \mathrm{C}$ for about $1 \mathrm{~h}$. Eventually, through physical absorption onto PEDOT: PSS/rGO based electroactive paper the CEA antibodies are immobilized which is the affable biomarker for lung cancer. They found the sensor has a high sensitivity of $25.8 \mu \mathrm{Ang}-1$ $\mathrm{mL} \mathrm{cm}-2$ with a detection range of $2-8 \mathrm{ng} / \mathrm{mL}$. The hybridization between the polymer and rGO enhances the electrical conductivity and also improve electrochemical performance along with the signal stability.

A water-dispersible graphene/amphiphilic pyrene (PPYGR) derivative modified with gold nanoparticles (AuNPs) nano-composite for sensitive detection of CEA which is a label-free impedimetric immunosensor [42]. They functionalized the graphene through noncovalent attachment by using water-soluble 4 -armed poly (ethylene glycol)-NH2 (PEG) and pyrene butyric acid (PY) to manufacture PPYGR nano-composite. The produced PPYGR nano-composite exhibits an improvement in graphene hydrophilicity and loading capacity of AuNPs. This strategic also shows efficiency in immobilizing the CEA antibodies onto the AuNPs/PPYGR nanocomposite. Thus, the monoclonal CEA antibody (anti-CEA) was immobilized onto the AuNPs/ PPYGR nanocomposite using drop casts technique which takes $12 \mathrm{~h}$ for incubation at $35{ }^{\circ} \mathrm{C}$ as for the sensing platform. The as-fabricated sensor exhibits an excellent detection performance with a a wider range of response $(0.1-1000 \mathrm{ng} / \mathrm{mL})$ to detect CEA with a detection limit of $0.06 \mathrm{ng} / \mathrm{mL}$.

Wang et al. [43] (2017) fabricated an electrochemical immunosensor based on bimetallic $(\mathrm{AgPt})$ nanorings modified with rGO forming (AgPt NRs-rGO) nanocomposite for CEA detection. Using drop a casting technique and followed by drying it in the air, the $\mathrm{AgPt}$ NRs-rGO suspension deposited onto a glassy carbon electrode. Then, they coated anti-CEA on the electrode surface followed by drying the electrode at $4{ }^{\circ} \mathrm{C}$ in the refrigerator. Finally, immersion into the bovine serum album (BSA) solution after washing the electrode with a phosphate buffer solution (PSA) and. The developed immunosensor shows very good performance having a wide linear range of $5 \mathrm{fg} / \mathrm{mL}-50 \mathrm{ng} / \mathrm{mL}$ for the detection of CEA and the low detection limit of 1.43 $\mathrm{fg} / \mathrm{mL}$, improved stability, enhanced reproducibility, and selectivity. Where the BSA works as blocking agent molecules to fill undesired spaces where no antibody is occupied.

Chen et al. [44] (2018) reported a three-dimensional electrochemical DNA biosensor based on 3D graphene functionalized with Ag nanoparticle for sensitive DNA detection. Where the highly conductive nanocomposite layer was characterized by using scanning and transmission electron microscopy, contact angle analysis and cyclic voltammetry. They combined 3D graphene (3D GF) and Ag NPs for CYFRA21-1 DNA detection as CYFRA21-1 DNA is a sensitive and specific marker for non-small cell lung cancer (NSCLC). Hence, the 3D GF/Ag NPs improved immobilization of DNA on the sensor and reduced the detection limit. Moreover, the 3D GF/AgNPs provide a favorable microenvironment to retain the bioactivity of immobilized probe ssDNA and effectively promote electron transfer owing to their excellent biocompatibility and good conductivity. Under optimal conditions, the proposed biosensor could detect target DNA down to $1.0 \times 10^{-14} \mathrm{M}$ with high sensitivity and the peak currents were linear with the logarithm of the concentration of target DNA from $1.0 \times 10^{-14}$ to $1.0 \times 10^{-7} \mathrm{M}$. Furthermore, in clinical trials, this $3 \mathrm{D}$ biosensing system detected CYFRA21-1 DNA in real lung cancer samples with satisfactory results.

An ultrasensitive electrochemical immunoassay strategy to detect neuron-specific enolase (NSE) with a triple signal amplification strategy biomarker was proposed, which combined 3D-GNS/CS as the matrix, OMCSi-Au materials as labels, and AuNPs-induced silver deposition on the immunosensor surface Fang et al. [46] (2019). The proposed immunosensor showed great performance for NSE with acceptable reproducibility, stability, reliable detection, and high sensitivity, it provides great potential in clinical application. Utilization of porous three-dimensional graphene-starch architecture (3D-GNS) on the immunosensor surface to construct a unique 3D immune-electrode, which would greatly accelerate electron transfer and capture more protein molecules and thus it enhances the sensitivity of the device. 3DGNS was prepared with starch as a crosslinking agent and stabilizer, which is biocompatible and environmentally friendly. After a sandwich-type immunoreaction, the OMCSi-Au labeled Ab2 was trapped on the surface of immunosensor, the high concentration of AuNPs with high dispersion greatly catalyze the deposition of silver nanoparticles. The deposited silver nanoparticles (AgNPs) could be tested directly with anodic stripping voltammetric analysis (ASV) in potassium chloride solution to monitor the immunoreactions. The linear detection range for the proposed sensor reported as $0.02 \mathrm{pg} / \mathrm{mL}$ to $35 \mathrm{ng} / \mathrm{mL}$ for neuron-specific enolase antigen and the detection limit of $0.008 \mathrm{pg} / \mathrm{mL}$. The satisfactory results obtained with high stability and sensitivity confirmed the 
practicality and promising applicability of this threedimensional graphene-starch architecture (3D-GNS) based immunosensor for clinical applications to allow for the early detection of cancer.

A new window and method for lung cancer detection has paved through with the introduction of a noninvasive salivary biosensor. Choudhary et. [45] reported the fabrication of ultrasensitive Graphene Oxide (GO) based electrochemical immunosensor for the very first time to detect human telomerase reverse transcriptase (hTERT) a lung cancer biomarker. They fabricated immuno-electrode by covalent immobilization of rabbit anti-hTERT antibodies (Ab) onto GO films on ITO coated glass. Moreover, GObased immunosensor exhibits specificity and low detection up to $10 \mathrm{ag} \mathrm{mL}-1(10 \times 10-18 \mathrm{~g} \mathrm{~mL}-1)$ in wide detection range (10 ag mL-1-50 ng mL-1) for hTERT corroborate by the electrochemical differential Pulse Voltammetry (DPV). The proposed immunosensor showed the potentiality for low-level detection of hTERT in biological fluids (lung/oral) samples. The uniform distribution of GO nanosheets; having large surface area enhanced the performance by efficient loading of antibodies.

\section{TABLE III}

BIOSENSORS BASED ON GRAPHENE NANOMATERIALS WITH DETECTION SPECIFICATIONS FOR LUNG CANCER

\begin{tabular}{|c|c|c|c|}
\hline $\begin{array}{c}\text { Biomar } \\
\text { ker } \\
\text { (Target) }\end{array}$ & Method & $\begin{array}{l}\text { Linear } \\
\text { range }\end{array}$ & $\begin{array}{c}\text { Detectio } \\
\text { n limit }\end{array}$ \\
\hline NSE & $\begin{array}{l}\text { Electrochem } \\
\text { ical }\end{array}$ & $\begin{array}{c}20 \text { fg } \mathrm{mL}- \\
1 \text { to } 35 \mathrm{ng} \\
\mathrm{mL}-1\end{array}$ & $\begin{array}{l}\text { ng mL-1 } \\
8 \text { fgmL-1 }\end{array}$ \\
\hline hTERT & $\begin{array}{l}\text { Electrochem } \\
\text { ical }\end{array}$ & $\begin{array}{c}10 \mathrm{ag} \mathrm{mL}- \\
1 \text { to } 50 \mathrm{ng} \\
\mathrm{mL}-1\end{array}$ & $\begin{array}{c}10 \text { ag mL- } \\
1\end{array}$ \\
\hline $\begin{array}{c}\text { CYFRA } \\
21-1\end{array}$ & $\begin{array}{l}\text { Electrochem } \\
\text { ical }\end{array}$ & $\begin{array}{c}1.0 \times 10^{-1} \\
{ }^{4} \mathrm{M} \text { to } \\
1.0 \times 10^{-7} \\
\mathrm{M}\end{array}$ & $\begin{array}{c}1.0 \times 10^{-1} \\
{ }^{4} \mathrm{M}\end{array}$ \\
\hline CEA & $\begin{array}{c}\text { Electrochem } \\
\text { ical } \\
\end{array}$ & $\begin{array}{c}5 \mathrm{fg} / \mathrm{mL} \text { to } \\
50 \mathrm{ng} / \mathrm{mL}\end{array}$ & $\begin{array}{c}1.43 \\
\mathrm{fg} / \mathrm{mL}\end{array}$ \\
\hline CEA & $\begin{array}{l}\text { Electrochem } \\
\text { ical }\end{array}$ & $\begin{array}{c}0.1 \text { to } \\
1000 \\
\mathrm{ng} / \mathrm{mL}\end{array}$ & $\begin{array}{r}0.06 \\
\mathrm{ng} / \mathrm{mL}\end{array}$ \\
\hline CEA & $\begin{array}{c}\text { Electrochem } \\
\text { ical }\end{array}$ & $\begin{array}{l}2 \text { to } 8 \\
\mathrm{ng} / \mathrm{mL}\end{array}$ & $\begin{array}{c}25.8 \\
\mu \text { Ang- } 1 \\
\mathrm{~mL} \mathrm{~cm}-2\end{array}$ \\
\hline
\end{tabular}

\section{Conclusion And Future Perspective}

As early-stage detection of lung cancer is arduous so it has the highest mortality rate within all types of cancers. About $70 \%$ of lung cancer cases are detected at the advanced stage and it can be detected through high-end equipment or invasive procedure like positron-emission tomography (PET) scan, computed tomography (CT) scan, magnetic resonance imaging (MRI), fluorescence bronchoscopy, mediastinoscopy, sputum cytology, needle biopsy (fine needle aspiration), blood tests, pulmonary function tests, immunological methods, however, the survival chances are often too low. Furthermore, these methods are only available at the selected hospital because of the expensiveness and required trained personnel.

In recent years, great advancements have been seen in the field of the biosensor, based on graphenenanomaterials aptitudes used in electrochemical biosensors, for the early-stage detection of lung cancer. Different kinds of graphene-based materials such as Graphene Oxide (GO) films, reduced Graphene Oxide (rGO), 3D graphene architectures, graphene-modified $\mathrm{Ag}, \mathrm{Au}$ nanomaterials have been introduced in this paper. graphene, in turn, makes cancer identification more sensitive, selective and accurate on account of its elegant versatility and outstanding properties. For example, high electrochemical performances are attributed due to the fast electron transfer and efficient immobilization of receptors on a large surface area (synergistic effects of nanocomposite hybridization) supported by the uniform distribution of graphene nanosheets. Though advances made in this area are exciting and encouraging in cancer detection the commercialization of such biosensor is still in its early stage for all aforementioned diseases. The drawbacks and challenges presented with graphene nanomaterials need to be overcome. For example, a universal method to synthesis graphene-based materials with desired size and layers; the production of a high-quality graphene layer with zero defect. However, other quasi-2D nanomaterials such as hexagonal boron nitride (h-BN) [56] and transition metal dichalcogenides like molybdenum disulfide $\left(\mathrm{MoS}_{2}\right)$ [58-61], niobium Selenide $\left(\mathrm{NbSe}_{2}\right)$ [57], tungsten disulfide $\left(\mathrm{WS}_{2}\right)$ [62] are widely studied by researchers for the development of biosensors. Recently, the $\mathrm{MoS}_{2}$ gets large attention among researches to develop electrochemical biosensors. It has additional advantages of the tunable bandgap and an easy exfoliation into a single layer- due to weak Van der Waals bonding force over pristine graphene. The hybridization between graphene and $\mathrm{MoS}_{2}$ would bring an extra high surface area and also expected to have an excellent electrocatalytic activity that is suitable for electrochemical applications [5861]. We would like to wind up by stating that there is still much room for the scientific research and technological development of graphene-related theory, material-matrices concerning the applications of graphene-based nanomaterials. 


\section{REFERENCES}

[1] C.G.A.R. Network, Integrated genomic and molecular characterization of cervical cancer, Nature, 543 (2017) 378-384.

[2] World Health Organization (WHO); Noncommunicable Diseases Country Profiles, 2018.

[3] J. Ferlay, E. Steliarova-Foucher, J. Lortet-Tieulent, S. Roso, J. Coebergh, H. Comber, D.Forman, F. Bray, Cancer incidence and mortality patterns in Europe: estimates for 40 countries in 2012, European journal of cancer, 49 (2013) 1374-1403.

[4] ] I. Palchetti, Affinity biosensors for tumor-marker analysis, Bioanalysis, 6 (2014) 3417-3435.

[5] B. Gupta, N. Kumar, Worldwide incidence, mortality and time trends for cancer of the oesophagus, European Journal of Cancer Prevention, 26 (2017) 107-118

[6] R.A. Smith, V. Cokkinides, D. Brooks, D. Saslow, O.W. Brawley, Cancer screening in the United States, 2010: a review of current American Cancer Society guidelines and issues in cancer screening, CA: a cancer journal for clinicians, 60 (2010) 99-119l

[7] Jin, Bing, et al. "Multi-nanomaterial electrochemical biosensor based on label-free graphene for detecting cancer biomarkers." Biosensors and Bioelectronics 55 (2014): 464-469.

[8] Hung, Lien-Yu, et al. "Microfluidic platforms for discovery and detection of molecular biomarkers." Microfluidics and nanofluidics 16.5 (2014): 941-963।

[9] Dalton, William S., and Stephen H. Friend. "Cancer biomarkers - an invitation to the table." Science 312.5777 (2006): 1165-1168.

[10] Henry, N. Lynn, and Daniel F. Hayes. "Cancer biomarkers." Molecular oncology 6.2 (2012): 140146.

[11] Diamandis, Eleftherios P. "Cancer biomarkers: can we turn recent failures into success?" Journal of the National Cancer Institute 102.19 (2010): 1462-1467.

[12] Ferlay, J.; Shin, H.R.; Bray, F.; Forman, D.; Mathers, C.; Parkin, D.M. Estimates of worldwide burden of cancer in 2008: GLOBOCAN 2008. Int. J. Cancer 2010. 127, 2893-2917.

[13] Sobue. T; Moriyama, N.; Kaneko, M.; Kusumoto, M.; Kobayashi, T.; Tsuchiya, R.; Kakinuma, R.; Ohmatsu. H.; Nagai, K.; Nishiyama, H.; et al. screening for lung cancer with low-dose helical computed tomography: Anti-Lung Cancer Association Project. J. Clin. Oncol. 2002, 20, 911-20.

[14] Goldstraw, P.; Crowley, J.; Chansky, K.; Giroux, D.J.; Groome, P.A.; Rami-Porta, R.; Postmus, P.E.; Rusch, V.; Sobin, L.; International Association for the Study of Lung Cancer International Staging Committee; et al. The IASLC Lung Cancer Staging Project: proposals for the revision of the TNM stage groupings in the forthcoming (seventh) edition of the TNM Classification of malignant tumours. J. Thorac. Oncol. 2007, 2, 706-714.

[15] Aberle, D.R.; Adams, A.M.; Berg, C.D.; Black, W.C.; Clapp, J.D.; Fagerstrom, R.M.; Gareen, I.F.; Gatsonis, C.; Marcus, P.M.; Sicks, J.D.; et al. Reduced lungcancer mortality with low-dose computed tomographic screening. N. Engl. J. Med. 2011, 365, 395-409.
[16] Rao CR, Sood AK, Subrahmanyam KS, Govindaraj A, Graphene: the new two dimentional nanomaterial; Angew ChemInt Ed 2009;48:7752-8.

[17] Su, C. Y. et al. Electrical and spectroscopic characterizations of ultra-large reduced graphene oxide monolayers. Chem. Mater. 21, 5674-5680 (2009).

[18] Liu, Q. et al. Graphene and Graphene Oxide Sheets Supported on Silica as Versatile and High-Performance Adsorbents for Solid-Phase Extraction. Angew. Chemie - Int. Ed. 50, 5913-5917 (2011).

[19] Geim, a K. Status and Prospects. Sci. (80-). 324, 15301534 (2009).

[20] Gilje, S. et al. Processable aqueous dispersions of graphene nanosheets. Nat. Nanotechnol. 3, 101-105 (2008).

[21] Stankovich, S. et al. Synthesis of graphene-based nanosheets via chemical reduction of exfoliated graphite oxide. Carbon N. Y. 45, 1558-1565 (2007).

[22] Paredes, J. I., Marti, a, Tasco, J. M. D. \& Mart1, a. Graphene Oxide Dispersions in Organic Solvents Graphene Oxide Dispersions in Organic Solvents. 24, 10560-10564 (2008).

[23] Gilje, S., Han, S., Wang, M., Wang, K. L. \& Kaner, R. B. A chemical route to graphene for device applications. Nano Lett. 7, 3394-3398 (2007).

[24] Liu, S. et al. Antibacterial Activity of Graphite, Graphite Oxide, Graphene Oxide, and Reduced Graphene Oxide: Membrane and Oxidative Stress. ACS Nano 5, 6971-6980 (2011).

[25] Bagri, A. et al. Structural evolution during the reduction of chemically derived graphene oxide. Nat. Chem. 2, 581- 587 (2010).

[26] Mascini, M., and S. Tombelli. "Biosensors for biomarkers in medical diagnostics." Biomarkers 13.7-8 (2008): 637-657.

[27] Wang, Joseph. "Electrochemical biosensors: towards point-of-care cancer diagnostics." Biosensors and Bioelectronics 21.10 (2006): 1887-1892.

[28] Chikkaveeraiah, Bhaskara V., et al. "Electrochemical immunosensors for detection of cancer protein biomarkers." ACS nano 6.8 (2012): 6546-6561.

[29] Thevenot, D. R., Toth, K., Durst, R. A. \& Wilson, G. S. Electrochemical biosensors: recommended definitions and classification. Biosens. Bioelectron. 16, 121-131 (2001).

[30] Labib, M., Sargent, E. H. \& Kelley, S. O. Electrochemical Methods for the Analysis of Clinically Relevant Biomolecules. Chem. Rev. 116, 9001-9090 (2016).

[31] Luo, X., Davis, J. J. \& Davis, J. J. Electrical biosensors and the label free detection of protein disease biomarkers. Chem Soc Rev (2013). doi:10.1039/c3cs60077g

[32] Paper, R. Electrochemical Biosensors - Sensor Principles and Architectures. 1400-1458 (2008).

[33] Thévenot, Daniel R., et al. "Electrochemical biosensors: recommended definitions and classification." Analytical Letters34.5 (2001): 635-659.

[34] Dong, W. et al. Synthesis of $\mathrm{Pb}$ nanowires- $\mathrm{Au}$ nanoparticles nanostructure decorated with reduced graphene oxide for electrochemical sensing. Talanta 165, 604-611 (2017).

[35] Wang, Z., Lee, S., Koo, K. \& Kim, K. Nanowire-Based Sensors for Biological and Medical Applications. IEEE Trans. Nanobioscience 15, (2016). 186-199

[36] Yang, C., Denno, M. E., Pyakurel, P. \& Venton, B. J. Recent trends in carbon nanomaterial-based 
electrochemical sensors for biomolecules: A review. Anal. Chim. Acta (2015) 887, 17-37.

[37] World Cancer Report 2014. (International Agency for Research on Cancer, 2014).

[38] Ho, J. A., Chang, H., Shih, N., Wu, L. \& Chang, Y. Diagnostic Detection of Human Lung CancerAssociated Antigen Using a Gold Nanoparticle-Based Electrochemical. (2010)82, 5944-5950.

[39] Zhao, F., Cheng, C. \& Xia, N. Electrochemical Techniques for the Detection of Cancer Cells and CellSurface Glycan Expression: A Mini Review. (2017).12, 7580-7596.

[40] Kumar, S. et al. Reduced graphene oxide modified smart conducting paper for cancer biosensor. Biosens. Bioelectron. (2015). 73, 114-122.

[41] Li, Y. et al. Water-dispersible graphene / amphiphilic pyrene derivative nanocomposite: igh $\mathrm{Au}$ Ps loading capacity for CEA electrochemical immunosensing. Sensors Actuators B Chem. (2017). 248, 966-972.

[42] Wang, A. R., Feng, J., Xue, Y., Wu, L. \& Wang, A. A label-free electrochemical immunosensor based on AgPt nanorings supported on reduced graphene oxide for ultrasensitive analysis of tumor marker. Sensors Actuators (2018). B. 254, 1174-1181.

[43] Li, Y. et al. Water-dispersible graphene / amphiphilic pyrene derivative nanocomposite: igh $\mathrm{Au}$ Ps loading capacity for CEA electrochemical immunosensing. Sensors Actuators B Chem. 248(2017), 966-972.

[44] Chen, Mei, et al. "Three-dimensional electrochemical DNA biosensor based on 3D graphene-Ag nanoparticles for sensitive detection of CYFRA21-1 in non-small cell lung cancer." Sensors and Actuators B: Chemical 255 (2018): 2910-2918.

[45] Choudhary, M. et al. Graphene Oxide based Label Free Ultrasensitive Immunosensor for Lung Cancer Biomarker, hTERT. J Biosens Bioelectron 4, 1-9 (2013).

[46] Fang, Yishan, Yanping Li, Ming Zhang, Bo Cui, Qiong $\mathrm{Hu}$, and Lishi Wang. "A novel electrochemical strategy based on porous 3D graphene-starch architecture and silver deposition for ultrasensitive detection of neuronspecific enolase." Analyst 144, no. 6 (2019): 2186-2194.

[47] Eivazzadeh-Keihan, Reza, et al. "Recent advances on nanomaterial based electrochemical and optical aptasensors for detection of cancer biomarkers." $\operatorname{Tr} A C$ Trends in Analytical Chemistry 100 (2018): 103-115.

[48] Rosamaria Capuano, Alexandro Catini, Roberto Paolesse, Corrado Di Natale; Sensors for Lung Cancer Diagnosis; J. Clin. Med. 2019, 8, 235; doi: 10.3390/jcm8020235.

[49] Taniselass, S., MK Md Arshad, and Subash CB Gopinath. "Graphene-based electrochemical biosensors for monitoring noncommunicable disease biomarkers." Biosensors and Bioelectronics (2019).

[50] Li, Jianping, Shuhuai Li, and Catherine F. Yang. "Electrochemical biosensors for cancer biomarker detection." Electroanalysis 24.12 (2012): 2213-2229.

[51] Topkaya, Seda Nur, Mostafa Azimzadeh, and Mehmet Ozsoz. "Electrochemical biosensors for cancer biomarkers detection: Recent advances and challenges." Electroanalysis 28.7 (2016): 1402-1419.

[52] Wang, Joseph. "Electrochemical biosensors: towards point-of-care cancer diagnostics." Biosensors and Bioelectronics 21.10 (2006): 1887-1892.

[53] Feng, Lingyan, et al. "A graphene functionalized electrochemical aptasensor for selective label-free detection of cancer cells." Biomaterials 32.11 (2011): 2930-2937.

[54] Jeffree, Amanina Iymia, et al. "Biosensors Approach for Lung Cancer Diagnosis-A Review." RITA 2018. Springer, Singapore, 2020. 425-435.

[55] Taniselass, S., MK Md Arshad, and Subash CB Gopinath. "Graphene-based electrochemical biosensors for monitoring noncommunicable disease biomarkers." Biosensors and Bioelectronics (2019).

[56] Hu, Tingting, Xuan Mei, Yingjie Wang, Xisheng Weng, Ruizheng Liang, and Min Wei. "Two-dimensional nanomaterials: fascinating materials in biomedical field." Science Bulletin (2019).

[57] Vilian, AT Ezhil, Bose Dinesh, Sung-Min Kang, Uma Maheswari Krishnan, Yun Suk Huh, and Young-Kyu Han. "Recent advances in molybdenum disulfide-based electrode materials for electroanalytical applications." Microchimica Acta 186, no. 3 (2019): 203.

[58] Chiu, Nan-Fu, and Shi-Yuan Fan. "Highly sensitive carboxyl-graphene oxide-based SPR immunosensor for the detection of CA19-9 biomarker." In Optical Sensors 2019 , vol. 11028, p. 110281T. International Society for Optics and Photonics, 2019.

[59] Yadav, Varnika, Shounak Roy, Prem Singh, Ziyauddin Khan, and Amit Jaiswal. "2D MoS2-Based Nanomaterials for Therapeutic, Bioimaging, and Biosensing Applications." Small 15, no. 1 (2019): 1803706.

[60] Chen, Changdong, Yunxiao Feng, Xichao Xia, Ming $\mathrm{La}$, and Binbin Zhou. "Recent Advances in Nanomaterials-Based Electrochemical Biosensors for MicroRNAs Detection." Int. J. Electrochem. Sci 14 (2019): 5174-5187.

[61] Wang, Yaoguang, Guanhui Zhao, Yong Zhang, Xuehui Pang, Wei Cao, Bin Du, and Qin Wei. "Sandwich-type electrochemical immunosensor for CEA detection based on Ag/MoS2@Fe3O4 and an analogous ELISA method with total internal reflection microscopy." Sensors and Actuators B: Chemical 266 (2018): 561-569.

[62] Yang, Jimin, Lei Gao, Cheng Peng, and Wei Zhang. "Construction of self-signal DNA electrochemical biosensor employing WS 2 nanosheets combined with PIn6COOH." RSC advances 9, no. 17 (2019): 96139619.

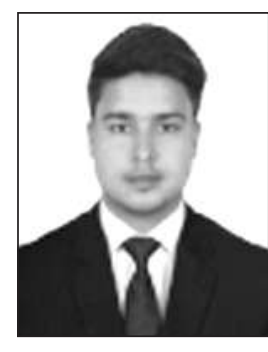

Masum Hossen obtained a B.Sc degree in Electrical and Electronic Engineering from the Green University of Bangladesh in 2019. After the completion of his graduation, he joined the same dept. as a lecturer of Green University of Bangladesh in January 2019. From January 2018 to December 2018, he was a Teaching Assistant with two very sophisticated professors (1. Pro. Vice Chancellor; 2. Dean of engineering faculty) form his department. He is also associated with the Research Innovation and Transformation (CRIT) and Energy\& material research cell (GUB). His research interest 
includes the study of 2-D materials; nanoelectronics for power.

applications (solar cell); biosensing/bioimaging using nanomaterials (nano biosensor), Bioelectronics, Nanobiophysics, Nanodevices, and technologies.

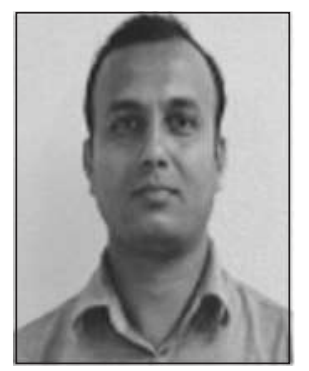

Md. Anwar Hossain (M’09) received the B. Sc. Engineering degree in Electrical and Electronic Engineering from the Rajshahi University of Engineering\& Technology, Rajshahi, Bangladesh in 2001, the M. E. degree in Information and Communication Technology from the Asian Institute of Technology in 2006, Pathumthani, Thailand, and the Ph.D. degree in Electronics and Information Engineering under Interdisciplinary Intelligent Systems Engineering from the University of the Ryukyus, Nishihara, Okinawa, Japan in 2013. He received Postdoctoral Fellowship from Japan Society for the Promotion of Science in 2015 and he is working as Associate Professor in Electrical and Electronic Engineering Department, Green University of Bangladesh, Dhaka, Bangladesh. Dr. Hossain is currently doing research with Electrical and Electronic Engineering Department, Independent University, Bangladesh (IUB), School of Electronics and Telecommunications, Hanoi University of Science and Technology, Vietnam and University of the Ryukyus, Okinawa, Japan. His research interests include Photonic Sensors, Biophotonics, Photonic Crystals
Fibers, Optoelectronic Devices and Systems, Antenna Array Signal Processing (Beamforming), CDMA, Optical CDMA, and OFDM.

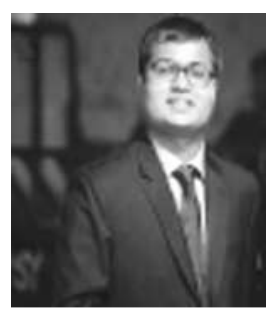

Prattay Kairy received the B.sc degree in Electrical and Electronics Engineering from Bangladesh University of Engineering and Technology (BUET). Currently, he is pursuing the Ph.D. degree in electrical engineering at the University of Utah, USA. From May, 2017 to July, 2018, he worked as a Lecturer in Electrical and Electronic Engineering Dept. in Green University of Bangladesh. At present, he is working as graduate research assistant in Electrical and Computer Engineering dept. in the University of Utah. His research interest focuses on nano-biosensor a biosensing /bioimaging device; nano-electrnoics based on Graphene. 